\title{
Clinical benefits of early cold therapy in accident and emergency following ankle sprain
}

\author{
J. P. SLOAN, R. HAIN \& R. POWNALL* \\ Accident and Emergency Department, University Hospital, Nottingham $\mathcal{E}{ }^{*}$ Clinical \\ Investigation, The Boots Company plc, Nottingham, England
}

\section{SUMMARY}

One hundred and forty-three patients presenting with ankle sprains within $24 \mathrm{~h}$ of injury were entered into a double blind study. Treatment consisted of a standardized regime of high dose non-steroidal anti-inflammatory medication and an elastic support for all patients, who were then randomly allocated to two groups. One group received immediate cold therapy, the other received simulated therapy. Assessments made at 7 days showed a trend in favour of the group receiving cold therapy, although this did not reach significance. It is concluded that cold therapy together with compression may have a beneficial effect but that a single application in the accident and emergency department is not justified when a background therapy of non-steroidal anti-inflammatory medication is given.

\section{INTRODUCTION}

Doctors who treat soft-tissue injuries of the ankle have a limited number of immediate treatments available. These include strapping, the application of hot or cold with or without compression and elevation, anti-inflammatory drugs, various creams and, assuming staff are available, more sophisticated therapy such as pulsed electromagnetic energy. Prompt action may help to control haemorrhage and oedema, and may even limit the inflammatory process at a cellular level (Brune et al., 1981), this bringing about a faster return to functional activity. This has been demonstrated in a study involving the administration of high dose non-steroidal anti-inflammatory medication to young adults within $6 \mathrm{~h}$ of their ankle sprains. The results indicated superior recovery when compared with administration at $48 \mathrm{~h}$ (Sloan et al., 1989). The fact that opposite

Correspondence: Mr F. P. Sloan, Accident and Emergency Department, General Infirmary, Leeds LS1 $3 E X$, England. 
treatments (i.e. heat and cold) may be applied underlines the fact that some of these treatments have little objective basis. Previous work in a human model of soft-tissue $\stackrel{\mathbb{D}}{Q}$ injury has shown that cooling alone does not produce a sustained reduction in swelling 3 and that the addition of mild pressure $(10-30 \mathrm{mmHg})$ to the cooling $\left(15^{\circ} \mathrm{C}\right)$ is necessary ? for any permanent effects to be seen (Sloan et al., 1988). Schmidt et al., (1979), using $\underset{\vec{S}}{\vec{S}}$ an experimental rat paw model, also found that cooling alone did not cause a reduction $\frac{}{0}$ in swelling.

Cold therapy is commonly employed in the early treatment of soft-tissue injuries. Its $\frac{\overrightarrow{5}}{\overrightarrow{5}}$ use appears to have been documented first by Hippocrates (460-377 BC), who $\stackrel{\circ}{\circ}$ described its pain-relieving effects (Hippocrates, 1931 translated by W. H. S. Jones). This analgesic effect has since been well documented (Evans, 1981). Other effects are $\overrightarrow{0}$ less clear. Although its use is widespread, there is little to support scientifically any other benefits. Hocutt et al., (1982) studied a group of 37 adults with severe ankle sprains. They were treated with either cold or heat therapy for $15 \mathrm{~min}$ three times per $\stackrel{\mathbb{D}}{3}$ day for 3 days. Full activity was reported in 13.2 days in those receiving cold therapy within $36 \mathrm{~h}$ of injury, compared with 30.4 days in a group receiving cold therapy after $\overrightarrow{\vec{J}}$ $36 \mathrm{~h}$. Heat therapy resulted in a recovery time of 33.3 days. However, the subgroups 9 were very small (between 3 and 11) and the study carried out in two centres, without any blinding, and, presumably with more than one observer. Matsen et al., (1975), looking at rabbit femoral fractures, and Jezdinsky et al. (1973), looking at rat paw trauma, failed to demonstrate any clinical benefits of cold therapy, and noted a tendency for the swelling to increase on withdrawal of the therapy. Schaubel (1946) documented the effects of cold (ice) therapy following 519 various orthopaedic procedures and recordeg that post-operative casts required splitting in $42 \%$ of the untreated group and in on $\frac{1}{8}$ $5 \%$ of those treated with cold therapy. There was no control of the injury severit between the groups, however, and control of pain in the cold therapy group may have resulted in the observed effects. Hayden (1964) treated 1000 patients suffering from minor injuries with ice and recorded that all responded well with $97 \%$ returning to work the same day. There was no control group, however. In the background of these inconclusive and inadequate studies, we felt that the relevance of cold therapy to accident and emergency medicine was not clear. This study was therefore undertaken to determine whether cold therapy, applied in accident and emergency departments, significantly influences outcome.

\section{METHODS}

Any patient aged between 16 and 50 years old who presented to the Accident and Emergency Department of the University Hospital, Nottingham, between March and $\stackrel{\sigma}{\sigma}$ October 1986, with an acute ankle sprain, was considered eligible for the study. The $\tilde{N}$ decision to enter was taken by a research physiotherapist $(\mathrm{RH})$ who was on duty in the $\underset{\omega}{\mathcal{W}}$ department during those times when acute ankle injuries most frequently presented,, and entry depended on actually receiving treatment within $24 \mathrm{~h}$ of injury.

Screening was performed by both the referring accident and emergency doctor and by the research physiotherapist. Any patient with a history of asthma or upper 0 gastrointestinal disturbance was excluded, as were those with chronic relapsing injuries, 
or any who had already been started on a course of medication. All patients underwent radiological examination of the ankle joint, including an anterior stress test (Pennel 1943; Glasgow et al., 1980) to exclude fractures and unstable joints. They were then examined by a single clinician (JPS) who was not involved in the administration of treatment, and an impression of severity was made and recorded. In addition, the range of movement of both ankles was measured using a purpose-built goniometer, described elsewhere (Muwanga et al., 1985). Patients were then randomly allocated to one of two treatment groups by the physiotherapist, using a predetermined sequence. One group received immediate physiotherapy, consisting of the application of a cooling anklet, inflated to $30 \mathrm{mmHg}$ for $30 \mathrm{~min}$, together with elevation of the ankle, while supine, at $45^{\circ}$. The other group received 'dummy physiotherapy' consisting of the application of a non-inflated anklet without elevation while supine for $30 \mathrm{~min}$. Both groups were given an immediate dose of $1200 \mathrm{mg}$ ibuprofen, thereafter receiving $2400 \mathrm{mg}$ total daily dose, scheduled as $1200 \mathrm{mg}$ in the morning and $600 \mathrm{mg}$ afternoon and evening. They were also given a supply of paracetamol $500 \mathrm{mg}$ tablets as supplementary analgesia. These two groups are subsequently referred to as the cold therapy and dummy therapy groups. The anklet was a freon-cooled device ('Cryopac', Cryomed Corp., Princeton, New Jersey, USA) and has been found by the authors to cool the skin temperature to approximately $15-20^{\circ} \mathrm{C}$. In addition, all patients were given written advice regarding rest and elevation of the injured ankle while at home. An elastic support ('ProSport', Seton Ltd, Oldham, UK) was given to all patients to continue compression and help stabilize the lateral ligament complex. The benefit of such supports over simple knitted hose has been demonstrated (Muwanga et al., 1986). Prior to leaving the Accident and Emergency Department, all patients were given a diary with detailed questions regarding pain, reaction to treatment and readiness to weight bear, each being answered daily. They were then given an appointment to return 7 days later.

On review the ankle was examined by the same clinician, who was unaware of treatment group, and a clinical impression of severity was again made. In addition, the range of movement of both ankles was measured, and a single AP X-ray of the injured ankle was taken. This was compared with the $\mathrm{X}$-ray taken at the initial visit and the softtissue swelling overlying the lateral malleolus was measured on each. A 'soft-tissue swelling index' was calculated for each $\mathrm{X}$-ray, being the ratio between the swelling and the intermalleolar distance, and this was recorded. We have found this is an accurate and reproducible means of assessing soft-tissue swelling. The diary was collected, and patients were either discharged at this point (and the medication discontinued), or a new diary given and an appointment made at 14 days.

At this visit, the same measurements were made except that the X-ray was not repeated.

Written consent was obtained from all patients and the study received the approval of the Nottingham University Hospital Ethical Committee.

\section{RESULTS}

One hundred and forty-three patients were entered into the study. The age at entry, sex 
ratio and time since injury were comparable for the treatments, with median values of 24 years of age, $79 \%$ male and $17 \mathrm{~h} 30 \mathrm{~min}$ from injury. Sports injuries accounted for $53 \%$ of the cases. On clinical assessment, $50 \%$ were rated as being either severe or very severe, these being unable to weight bear. Default at day seven was low with a total of 116 patients re-attending for assessment. Of these, $103(89 \%)$ were withdrawn at day 7 because of good recovery, and there was no statistical difference between the treatment groups in this respect. The overall incidence of ankle instability in all those patients referred to the research physiotherapist for screening was $8 \%$. The cooling anklet and elastic support were well tolerated by all patients.

Changes in the soft-tissue swelling index and the range of ankle movements were analysed by analysis of covariance (Armitage, 1971). Differences between treatments were analysed using the Wilcoxon Rank Sum Test with adjustment for ties unless otherwise stated. Individual component differences were as follows:

\section{Soft tissue swelling}

The index showed improvements by $46 \%$ at day 7 in the cold-therapy group, compared with $40 \%$ at day 7 in the dummy-therapy group. After analysis of covariance, the difference between these groups shows a probability value of 0.07 .

\section{Severity of injury}

Of the cold therapy patients, $88 \%$ had improved by two, three or four scale points (on a five point linear analogue scale) at day 7 compared with $79 \%$ in the dummy therapyo group. This trend does not reach statistical significance $(P=0.15$ Wilcoxon Rank Sum Test).

\section{Ability to weight bear}

There was a trend in favour of the cold therapy group with $36 \%$ of patients in this group improving by three or four scale units in the diary linear analogue compared with $29 \%$ in the dummy therapy group. Again, this trend fails to reach statistical significance $(P=0.64$ Wilcoxon Rank Sum Test).

\section{Time of follow-up}

Five patients required follow-up to 14 days in the cold therapy group compared with eight in the dummy treatment group. These differences are not significant.

\section{Range of movement}

There was no significant difference between the two groups in this respect.

\section{Pain-relief}

There was no significant difference between the groups in this regard, even within $1 \mathrm{~h}$ from treatment. 


\section{DISCUSSION}

This study has compared cold and compression with placebo in the presence of a background therapy of non-steroidal anti-inflammatory drugs in the management of soft-tissue swelling, and a trend has emerged in favour of the cold therapy, though this is not significant. The fact that previous studies have produced variable results is probably because compression was not controlled and often absent. Compression is probably important in controlling vascular beds that are abnormally permiable, thereby reducing protein leakage.

The changes demonstrated are fairly small and probably do not have any clinical significance. However, this study was designed with a single, minimal cold therapy, as this is the only way mass treatment would be practicable in accident and emergency departments. It is possible that more prolonged cooling together with compression produces improvements of greater significance and, a further clinical trial may be warranted to determine if this is the case. This study shows, however, that a single 30min period of treatment in the accident and emergency department cannot be justified, though advice to paramedics, sports trainers and patients themselves to give and continue cold and compression is probably more important.

\section{ACKNOWLEDGEMENT}

This study was partly funded by a grant from the Royal College of Surgeons of England.

Trial supplies were kindly supplied by the Boots Company plc.

\section{REFERENCES}

Armitage P. (1971) Statistical Methods in Medical Research, Chapter 9, pp. 288-301 \& Chapter 4, pp. 131-5. Oxford, Blackwell Scientific Publications.

Brune, K., Rainsford K. D., Wagner K. \& Peskar B. A. (1981) 'Inhibition by anti-inflammatory drugs of prostaglandin production in cultured macrophages.' Archives of Pharmacology 315, 269-78.

Evans, P. J. D. (1981) Cryo-analgesia. Anaesthesia 36, 1003-13.

Glasgow M., Jackson A. \& Jamieson A. M. (1980) Instability of the ankle after injury to the lateral ligaments. fournal of Bone and foint Surgery 62B, 196-200.

Jezdinsky J., Marek J. \& Ochansky P. (1973) Effects of local cold and heat therapy on traumatic oedema in the rat hind paw. Acta Universitatis Olomucensis Palackiane Facultatis Medicae 66, 185-228.

Hayden C. A. (1964) Cryokinetics in an early treatment programme. fournal of the American Physical Therapy Association 44, 990-3.

Hippocrates (1931) Heracleitus on the Universe. In Aphorisms (Vol. 4) Translated by W. H. S. Jones. London, Heinemman.

Hocutt J. E., Jaffe R., Rylander C. R. \& Beebe J. K. (1982) Cryotherapy in Ankle Sprains. American fournal of Sports Medicine 10, 316-19.

Matsen F. A., Quested K. \& Matsen A. L. (1975) The effects of local cooling on post fracture swelling. Clinical Orthopaedics 109, 201-6.

Muwanga C. L., Dove A. F. \& Plant G. R. (1985) The measurement of ankle movements-a new method. Injury 16, 312-14.

Muwanga C. L., Quinton D. N., Sloan, J. P., Gillies P. \& Dove A. F. (1986) A New Treatment of Stable Lateral Ligament Injuries of the Ankle Joint. Injury 17, 380-2. 
Pennel G. F. (1943) Subluxation of the ankle. Canadian Medical Association fournal 49, 92-5.

Schaubel H. J. (1946) The local use of ice after orthopaedic procedures. Amerian fournal of Surgery 72, 711- $\frac{\mathbb{Q}}{6}$ 14.

Schmidt K. L., Off V. R., Rocher G. et al. (1979) Heat, cold and inflammation. Rheumatology 38, 391-404. Sloan J. P., Hain R., Pownall R. (1989) The benefits of early antiflammatory medication following ankle sprains. Injury (In press.)

Sloan J. P., Hain R. \& Giddings P. (1988) Effect of cold and compression on edema. Physician and Sports Medicine 16, 116-20. 